\title{
Pengolahan Singkong Menjadi Brownies Untuk Meningkatkan Nilai Jual Singkong di Desa Tegalharjo Kecamatan Glenmore Kabupaten Banyuwangi
}

\author{
Siti Aimah' ${ }^{1}$, Nawal Ika Susanti ${ }^{2}$, Lely Ana Ferawati Ekaningsih ${ }^{3}$ \\ ${ }^{1}$ Fakultas Tarbiyah dan Keguruan, ${ }^{2,3}$ Fakultas Ekonomi dan Bisnis Islam \\ IAI Darussalam Blokagung Banyuwangi \\ Email: 1 sitiaimah1@iaida.ac.id., 2nawalika@iaida.ac.id, \\ 3lelyanaferawatiekaningsih@iaida.ac.id
}

\begin{abstract}
Tegalharjo village is a village in Glenmore sub-district, Banyuwangi district, which has a very large plantation area with a variety of plants. One of the plants that thrives on plantations and people's homes is the cassava tree. But the use of cassava as a village's potential to improve the economy of citizens is less than optimal. Cassava is generally left to rot in the trees, sometimes sold cheaply with a maximum price of $R p 3.000 .00$ a kilo gram and even ironically it is only used as animal feed. Meanwhile the majority of housewives only depend on the family economy for their husbands' work as farmers, farm laborers, very few who are self-employed and plantation labour majority. Seeing this, there needs to be innovations that can increase the economic value of cassava. One of them by processing cassava into brownies. After being processed into brownies, the selling value automatically increases from a kilo of $R p 3.000,00$ to $R p 10,000.00$ in a package. This innovation was carried out by the service team through mentoring activities and training in making Brownies of Cassava.
\end{abstract}

Keywords: Efforts, Improve the Economy, Innovation, Cassava, Brownies

\section{Pendahuluan}

Masyarakat Dusun Krajan Desa Tegalharjo Kecamatan Glenmore Kabupaten Banyuwangi cenderung pasrah terhadap keadaan dan kondisi fisik yang selama ini membelenggu mereka. Selain itu, mereka juga cenderung hidup mengikuti arus dan kebiasaan yang selama ini telah berlaku dan diwariskan oleh nenek moyang mereka. Sedangkan keinginan untuk berinovasi dan berubah ke arah yang lebih baik sangat minim karena masyarakat Dusun Krajan sudah terlanjur merasa nyaman dengan kehidupan

Pengolahan Singkong Menjadi Brownis Untuk Meningkatkan Nilai Jual Singkong 
yang telah mereka jalani. Sehingga hal itu bisa berpengaruh terhadap kualitas kehidupan masyarakat DusunKrajan sendiri.

Berdasarkan data desa jumlah penduduk desa Tegalharjo pada tahun 2019 tercatat sebanyak 10.431 jiwa, terdiri atas 4814 jiwa laki-laki dan 5617 jiwa perempuan yang tersebar di lima dusun. Sedangkan tingkat pendidikan penduduk usia kerja di desa Tegalharjo mengalami peningkatan paling banyak adalah pada jenjang SMP sederajat yaitu mencapai 27.21 persen dari total jumah angkatan kerja di desa Tegalharjo, rinciannya adalah sekitar 12,12 persen tidak tamat SD dan 15,0 persen tamat SD. Sedangkan yang tamat SLTP sederajat 44,83 persen, yang tamat SLTA sekitar 20,61 pesen dan sisanya adalah Pergurun Tinggi yaitu sekitar 7, 34 persen. $^{1}$

Perekonomian masyarakat desa Tegalharjo selama ini bertumpu pada sektor pertanian dan perkebunan dengan mata pencaharian sebagian besar adalah sebagai buruh kebun yaitu sekitar 3.947 orang. Sedangkan yang bermata pencaharian lain meliputi petani sebanyak 2.263 orang, pedagang sebanyak 69 orang, PNS/TNI/POLRI sebanyak 26 orang sedangkan lainnya bekerja disektor informal meliputi tukang batu, pedagang keliling, tukang becak, dan montir. ${ }^{2}$

Masyarakat Dusun Krajan Desa Tegalhajo mayoritas bekerja sebagai petani dan Buruh. Potensi hasil pertanian yang bisa dikembangkan untuk mendukung perekonomian masyarakat Dusun Krajan Desa Tegalharjo memiliki potensi yang cukup baik, yaitu: melimpahnya singkong, cabai, tomat, padi, dan lainya. Namun banyak kendala yang menyebabkan dusun ini lambat berkembang, diantaranya ialah murahnya pemasaran hasil panen serta tidak ada lembaga pengelola potensi alam, sehingga masyarakat Dusun Krajan hanya mengandalkan harga jual tengkulakyang hanya dijual mentah. Hal ini disebabkan tidak adanya tenaga ahli dan kelompok masyarakat yang

\footnotetext{
${ }^{1}$ Tim Penyusun Profil Desa Tegalharjo, tahun 2019

${ }^{2}$ BPS Kabupaten Banyuwangi. Banyuwangi dalam angka tahun 2019

Pengolahan Singkong Menjadi Brownis Untuk Meningkatkan Nilai Jual Singkong di Desa Tegalharjo Kecamatan Glenmore Kabupaten Banyuwangi Siti Aimah, Nawal Ika Susanti, Lely Ana Ferawati Ekaningsih
} 
mengolah hasil bumi. Selain itu masyarakat Dusun Krajan kurang memiliki koneksi dengan pihak luar untuk menjual hasil panen yang diperoleh.

Tidak adanya kelompok usaha mikro atau koperasi petani juga menjadi kendala berarti bagi warga Dusun Krajan. Karena bagaimanapun juga, segala bentuk kegiatan pertanian seharusnya memiliki wadah atau koperasi yang mampu mengolah. Penghasilan masyarakat Dusun Krajan Desa Tegalharjo cukup untuk memenuhi kebutuhan sehari-hari karena di dusun ini banyak tersedia sumber bahan pokok yang bisa dikonsumsi seperti: beras, sayur, singkong, dan lainya.

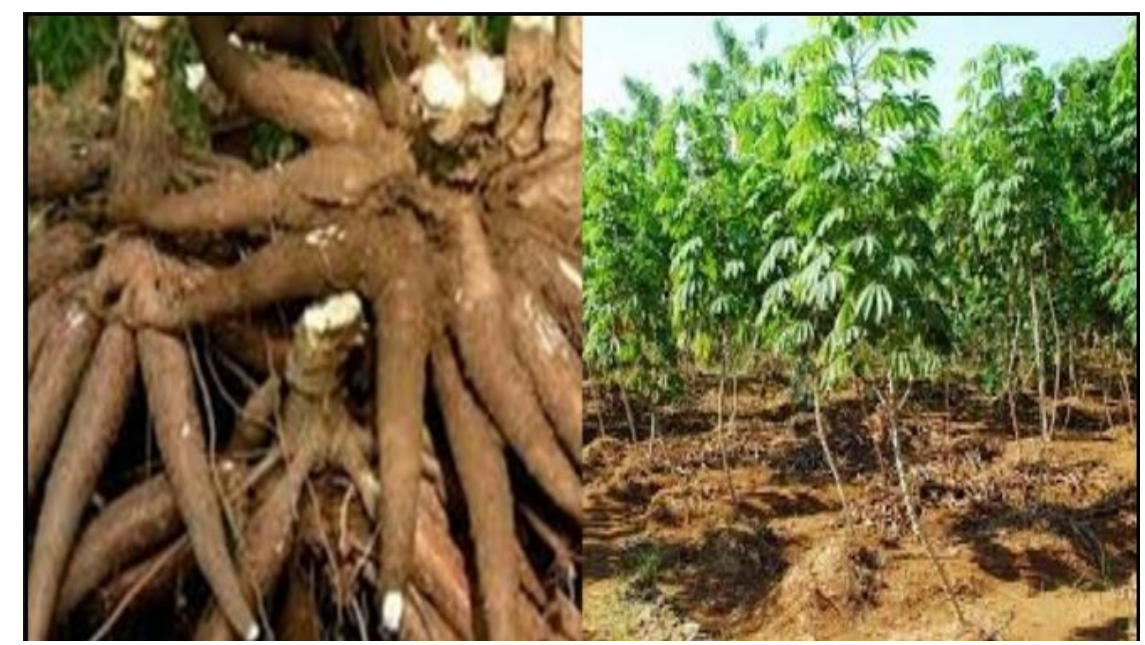

Gambar 1: Pohon Singkong Tumbuh Subur di Perkebunan Warga (Sumber: Dokumentasi di Lapangan, 2019)

Setiap panen mereka menyisihkan sebagian hasil panennya untuk kebutuhan sehari-hari dan sebagian banyak untuk dijual. Sebagian lainnya hasil dari singkong disimpan dan dibagikan kepada tetangga-tetangga dan juga di jual. Satu kilo singkong dijual Rp.3000. Jika warga sekitar mampu membuat makanan olahan singkong secara mandiri dapat mengangkat ekonomi sehingga pendapatan yang dihasilkan lebih meningkat. Maka perekonomian petani singkong di Dusun Krajan lebih baik dan terus 
meningkat, sehingga untuk kedepannya warga Dusun Krajan dapat menciptakan usaha mikro yang hasilnya lebih meningkatkan kesejahteraan hidup serta kekuatan ekonomi Desa Tegalharjo Dusun Krajan.

Salah satu upaya untuk membangkitkan pemikiran yang kurang berkembang penduduk Dusun Krajan Desa Tegalharjo adalah dengan memberikan kepercayaan bahwa produk-produk yang bisa mereka hasilkan dari kreatifitas tangan mereka. Melihat banyaknya singkong (ubi jalar) yang hanya dijual mentahan kepada tengkulak, ada inisiatif dari warga desa dan didukung oleh pemerintah desa untuk pemanfaatan potensi ubi jalar tersebut. Kami sebagai fasilitator memberikan pendampingan dalam pengembangan produksi singkong (ubi jalar) menjadi brownies khas Dusun Krajan Desa Tegalharjo yang dijual dengan harga per kemasan Rp. 10.000,00.

Hal tersebut dilatarbelakangi oleh banyaknya makanan-makanan yang tersedia di pasar desa saat ini sangat beraneka ragam dan harga yang ditawarkan juga beraneka dari yang terjangkau oleh masyarakat hingga harga yang tinggi. Salah satu jenis makanan atau cemilan yang digemari masyarakat. Banyak hal yang menjadikan Brownies sebagai salah satu primadona makanan manis, misalnya sangat cocok untuk cemilan, pengganjal perut sebab brownies mengandung banyak karbohidrat (apalagi jika terbuat dari singkong) dan glukosa untuk menambah energi dalam beraktivitas. Bahkan untuk mengisi perut kosong sebelum makan pun juga bisa. Selain dapat dikonsumsi oleh orang dewasa, Brownies juga banyak dikonsumsi oleh anak-anak dan remaja. Sehingga dari berbagai lapisan masyarakat sebagian besar menyukainya. Berdasarkan pemikiran inilahmuncullah ide untuk membuat dan mengembangkan usaha produksi makanan berupa jajanan brownies dengan bahan dasar singkong yang memang banyak ditemukan di perkebunan Dusun Krajan Desa Tegaharjo Kecamatan Glenmore Kabupaten Banyuwangi. 


\section{Metode}

Strategi yang dilaksanakan dalam mewujudkan kondisi yang diharapkan tersebut melalui metode PAR (Participatory Action Research) yakni sebuah metode dengan empat tahap pelaksanaan yaitu : (1) To Know, mengetahui terlebih dahulu potensi desa dan masyarakatnya; (2) To Understand, yakni memahami keinginan, harapan dan yang dibutuhkan masyarakat pada kegiatan pendampingan; (3) To Plan, yaitu merecanakan kegiatan pendampingan meliputi model, metode dan startagi pelaksanannya; (4) To Action and Reflection, maksudnya aksi nyata dampingan dengan melakukan kegiatan sesuai yang direncanakan berdasarkan potensi desa dan ekspektasi masyarakat desa bekerjasama dengan stakeholder terkait. ${ }^{3}$

Pihak yang terlibat dan bentuk keterlibatannya adalah sebagaimana pemaparan berikut ini:

1. Camat Glenmore, bentuk keterlibatannya yaitu melakukan pemantauan pada proses pendampingan yang dilakukan oleh tim pengabdian serta tindak lanjut atas kegiatan tersebut

2. Kepala desa Tegalharjo, bentuk keteribatannya adalah dengan mengevaluasi proses pendampingan dan memberikan arahan agar kegiatan pendampingan tersebut benar-benar nyata mewujudkan keinginan masyarakat yang ingin lebih berdaya dalam masalah ekonomi

3. Kader PKK desa Tegalharjo, bentuk keterlibatannya adalah memotivasi ibu-ibu rumah tangga desa Tegalharjo dalam kegiatan pendampingan oleh tim pengabdian melalui turut serta hadir dalam proses pendampingan dan pelatihan pembuatan Brownies berbahan singkong.

4. Ibu Nanik adalah seorang pengusaha berbagai macam kue, kue yang diproduksi telah merambah ke berbagai wilayah. Ibu Nanik termasuk dalam khalayak sasaran program "pengolahan singkong menjadi brownies

\footnotetext{
${ }^{3}$ Tim Penyusun, 2019, Pedoman Kuliah Kerja Nyata Partisipatory Action Research (KKN-PAR), LPPM-IAIDA, IAIDA Press, Banyuwangi 
singkong untuk meningkatkan nilai jual singkong di Desa Tegalharjo" karena diharapkan dengan adanya program ini mampu memberikan pengetahuan, menambah macam-macam kue yang diproduksi sekaligus membantu dalam pemasaran brownies singkong itu sendiri

5. Mbok Wi merupakan salah satu dari sekian banyak warga Desa Tegalharjo ynag memiliki kebun singkong. Selama ini mbok Wi menanam singkong hanya sekedar untuk dijual dalam bentuk singkong semata dengan harga yang tidak menentu tanpa adanya inovasi-inovasi untuk lebih meningkatkan nilai jual singkong itu sendiri. Maka dari itu semoga dengan terlaksananya program "pengolahan singkong menjadi brownies singkong untuk meningkatkan nilai jual singkong di Desa Tegalharjo" dapat meningkatkan nilai jual singkong sekaligus meningkatkan penghasilan bagi Mbok Wi pada khususnya.

\section{Hasil dan Diskusi}

Kegiatan pendampingan ini dilakukan atas kerjasama yang baik dari seluruh stakeholder terkait melalui tahapan-tahapan berikut ini:

1. Observasi Potensi Desa Tegalharjo

Langkah awal yang dilakukan adalah observasi. Observasi ini dilakukan untuk menggali pengetahuan tentang potensi Dusun Krajan Desa Tegalharjo dan permasalahan yang terdapat di dalamnya.

2. Menyimpulkan Hasil Observasi

Setelah observasi, maka dapat disimpulkan bahwa potensi paling unggul terdapat pada sumberdaya alamnya yang melimpah dari hasil kebun yaitu singkong serta mayoritas penduduk Dusun Krajan Desa Tegalharjo berprofesi sebagi petani dan buruh perkebunan.

3. Pendekatan Kepada Masyarakat dan Tokoh Masyarakat Desa Tegalharjo Pendekatan ini dilakukan dengan tujuan tim pengabdian bisa membaur dengan masyarakat sehingga bisa mendalami permasalahan yang 
ditemukan serta membangun komunikasi dengan masyarakat dan khususnya tokoh-tokohnya.

4. Pendataan Masyarakat Dusun Krajan Desa Tegalharjo

Pendataan ini diperlukan untuk mengetahui seberapa banyak masyarakat yang mempunyai kebun singkong dan memiliki waktu luang yang lebih banyak serta sangat membutuhkan pemberdayaan dan kreatifitas agar masyarakat bisa produktif menghasilkan karya yang bernilai dan laku dijual. Dari pendataan ini dapat disimpulkan bahwa seiktar 25 warga Dusun Krajan Desa Tegalharjo yang memiliki pohon pepaya memiliki waktu luang yang lebih banyak.

5. Perencanaan Program Pendampingan

Setelah data diperoleh, maka langkah selanjutnya adalah menyusun rencana program pendampingan sebagai solusi atas permasalahan yang diprioritaskan. Adapun program pendampingannya adalah optimalisasi pemanfaatan singkong menjadi Brownies dengan tema "Pengolahan Singkong Menjadi Brownies Untuk Meningkatkan Nilai Jual Singkong di Dusun Krajan Desa Tegalharjo".

6. Praktik Pembuatan Brownies Singkong Oleh Tim Pengabdian Kegiatan ini dilakukan sebelum sosialisasi kepada masyarakat dan stakeholders yang dilakukan oleh tim pengabdian dengan arahan tenaga ahli.

7. Pendampingan dan Pelatihan Pembuatan Brownies kepada Stakeholders dan Warga Dusun Krajan Desa Tegalharjo.

Pelatihan pemanfatan singkong menjadi olahan dalam bentuk Brownies yang mempunyai nilai jual lebih tinggi dibanding dijual mentahnya yang belum diolah. Proses pembuatan Brownies tersebut dimulai dengan pembuatan adonan, pencetakan, pengukusan, pemberian keju dan pengemasan. 
8. Pendampingan dan Evaluasi Indikator Keberhasilan dalam Pemanfaatan Singkong Menjadi Brownies.

Setelah pelatihan dan sosialisasi maka diharapkan para masyarakat Dusun Krajan Desa Tegalharjo yang mempunyai banyak waktu luang mampu memanfaatkan sumber daya alam yang ada yaitu olahan singkong menjadi Brownies sebagai salah satu sumber penghasilan dan menjadikan masyarakat yang lebih produktif. Untuk kelancaran pemasaran dari hasil kreatifitas didampingi ketika memasarkan dengan menghubungkan dengan kelompok masyarakat, ataupun pedagang yang mau dititipi Brownies. Adanya Brownies ini merupakan sebuah inovasi terbaru yang diharapkan bisa membawa perubahan pada perekonomian masyarakat Dusun Krajan Desa Tegalharjo.

9. Pelabelan Produk Brownies Singkong

Sebelum dipasarkan, maka produk yang sudah jadi diberi label terlebih dahulu agar lebih menarik dan layak dipasarkan.

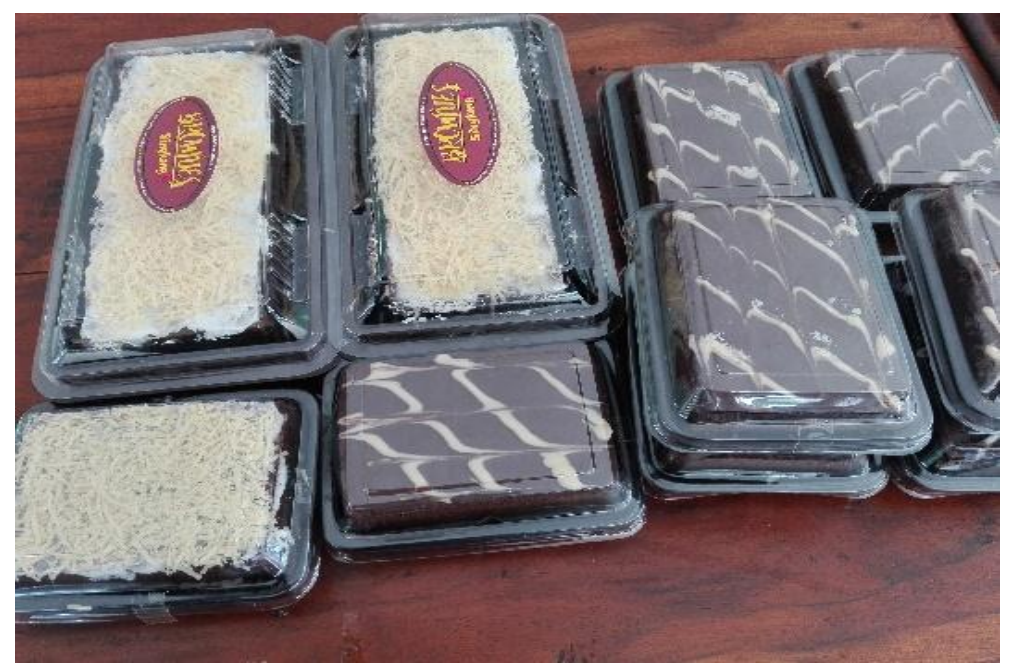

Gambar 2: Brownies Singkong Sebelum dan Sesudah Diberi Label (Sumber: Dokumentasi, 2019) 
10. Pemasaran

Dilakukan dengan tujuan mengetahui daya tarik warga untuk membeli Bronis Singkong. Objek dari kegiatan ini adalah pemilik toko sekitar desa. Brownies Singkong yang sudah dikemas dititipkan ke pemilik toko untuk dipasarkan. Kegiatan ini juga melibatkan beberapa kelompok ibu-ibu masyarakat Dusun Krajan Desa Tegalharjo yang nantinya akan meneruskan produksi Brownies Singkong ini.

11. Menyusun Struktur Kepengurusan Home Industri Brownies Singkong Setelah semua tahapan selesai, maka tahap terakhir adalah menyusun kepengurusan home industry Brownies Singkong. Hal ini bertujuan agar setelah tim pengabdian kembali, tetap ada yang meneruskan dan memonitoring produksi Brownies singkong. Adapun strukturnya sebagai berikut:

Ketua : : Ibu Nanik

Wakil : : Ibu Wiwik

Sekretaris : Ibu Wiwin

Bendahara : Ibu Neli

Seksi-seksi : 1. Seksi Pemasaran dan Monitoring : Ibu Mis
2. Seksi Produksi
: Ibu Sofiatun
3. Seksi Humas
: Ibu Sani

Setelah semua tahapan kegiatan dampingan terealisasi, maka perlu diadakan evaluasi yang kemudian hasilnya diapaparkan berikut:

1. Program ini merupakan sebuah inovasi baru yang bisa meningkatkan perekonomian warga Dusun Krajan Desa Tegalharjo

2. Singkong yang semula nilai jualnya sangat murah berubah menjadi mewah setelah diadakannya kegiatan pendampingan ini 
Ada beberapa kendala sekaligus solusi dalam kegiatan pendampingan pada masyarakat Dusun Krajan Desa Tegalharjo dideskripsikan pada keteranganberikut:

1. Kendala:

a. Kurangnya peralatan untuk pembuatan brownies singkong;

b. Banyaknya kegiatan ibu-ibu PKK, sehingga sangat sulit mencari waktu bagi ibu-ibu PKK untuk ikut berpartisipasi dalam pelaksanaan program tersebut;

c. Kurangnya pengalaman dalam pembuatan Brownies singkong.

\section{Solusi :}

a. Bekerjasama dengan masyarakat Desa Tegalharjo yang mempunyai peralatan untuk pembuatan brownies singkong;

b. Melakukan musyawarah dengan ibu-ibu PKK untuk mencari waktu yang tepat untuk bisa ikut berpartisipasi dalam pembuatan brownies singkong;

c. Menambah pengalaman dan pengatahuan dengan cara mengumpulkan resep-resep brownies singkong dari berbagai media dan terus melakukan percobaan pembuatan untuk hasil yang terbaik.

\section{Simpulan}

Berakhirnya tahapan dalam melaksanakan program pendampingan pada masyarakat Dusun Krajan Desa Tegalharjo Kecamatan Glenmore Kabupaten Banyuwangi, maka dapat disimpulkan bahwa masyarakat desa Tegalharjo masuk dalam kategori penghasilan menengah ke bawah. Hal ini di sebabkan karena beberapa faktor diantaranya; minimnya Sumber Daya Manusia (SDM) itu, kurangnya pemberdayaan dari pemerintah yaitu tidak adanya pelatihan secara intensif guna meningkatkan Sumber Daya Manusia termasuk dalam upaya pemanfatan potensi yang dimiliki. Pasca adanya program pendampingan tersebut yakni dengan pemanfaatan singkong yang 
merupakan potensi besar yang dimiliki pada lahan perkebunan menjadi olahan makanan berupa Brownies Singkong yang merupakan makanan yang banyak digemari masyarakat mulai anak-anak, remaja dan dewasa, maka mulai tumbuh semangat masyarakat untuk meningkatkan perekonomian melalui home industri.

Problematika yang ada di desa Tegalharjo ini tentunya dapat berimbas pada kegiatan sehari-hari masyarakat. Untuk mengatasinya seharusnya pemerintah daerah kabupaten Banyuwangi perlu mengadakan pelatihanpelatihan secara intensif baik pelatihan untuk bekal berproduksi maupun pelatihan dalam hal pemasaran hasil produksi melalui Dinas Perindustian, Perdagangan dan UMKM. Harapannya dengan banyaknya pelatiahan dan pengembangan UMKM masyarakat Dusun Krajan Desa Tegalharjo mampu untuk memproduksi potensi yang dimiliki dan meningkatkan taraf ekonomi secara mandiri serta mampu bersaing dengan pasar lokal maupun nasional, sehingga hilanglah persepsi masyarakat bahwa wirausaha adalah hal yang sulit dan berisiko tinggi atas pengetahuan dan pengalaman mereka lebih berani menghadapi resiko dalam berwirausaha.

\section{Rekomendasi}

Rekomendasi dari kegiatan pendampingan pemanfaatan Singkong menjadi Brownies agar meningkat nilai jualnya untuk membantu peningkatan perekonomian terhadap masyarakat Dusun Krajan Desa Tegalharjo Kecamatan Glenmore Kabupaten Banyuwangi adalah:

1. Ibu-ibu PKK

Dari pihak desa khususnya ibu-ibu PKK menanggapi baik yang kami lakukan mengenai pengolahan singkong menjadi brownis singkong sebagai salah satu sumber penghasilan untuk meningkatkan ekonomi yang ada di mayarakat Desa Tegalharjo. 
2. Kepala Desa

Perlu adanya sebuah dorongan yang tentunya sangat dibutuhkan masyarakat untuk membantu memajukan dan mensejahterakan Desa Tegalharjo dengan pengolahan singkong yang didapat dari warga menjadi brownis yang mayoritas sangat disukai warga.

3. Petani Singkong

Jangan berkecil hati dengan rendahnya harga penjualan singkong karena harapan dari desa akan berusaha memanfaatkan segala potensi yang dimiliki Desa yang nantinya kembali pada masyarakat desa itu sendiri termasuk melalui pengolahan singkong menjadi brownies singkong yang membuat nilai jual singkong meningkat pesat.

\section{Daftar Referensi}

BPS Kabupaten Banyuwangi. Banyuwangi dalam Angka Tahun 2019

Tim Penyusun, Profil Desa Tegaharjo kecamatan Glenmore kabupaten Banyuwangi Tahun 2019

Tim Penyusun, Pedoman Kuliah Kerja Nyata Partisipatory Action Research (KKN-PAR), LPPM-IAIDA, Banyuwangi : IAIDA Press, 2019. 